\section{REVIEWERS:}

- Amosun, Dele

- Barnes, Rolene

- Burgess, Theressa

- Chetty, Laran

- Constantinou, Dimitri

- David, Helen

- Diener, Ina

- Eales, Celie

- Erenzen, Dawn

- Fearnhead, Lynn

- Frantz, Jose

- Gilder, Narina

- Hanekom, Susan

- Human, A

Inglis, G

- Jelsma, Jennifer

- Jordaan, Ronel

- Joughin, Helen

- Louw, Quinette

- Maart, Soraya

- Maleka, Morake

- Marais, AM

- Mbambo, Nonceba

- M'Kumbuzi, Vyvienne

- Mostert, Karien

- Mothabeng, Joyce

Mtshali, B

- Myezwa, Hellen

- Naidoo, Nirmala

- Naude, Benita

- Parker, Romy

- Paulsen, Tom

- Pharaoh, H

- Phillips, Julie

- Potterton, Joanne

- Puckree, Lina

- Rhoda, Anthea

- Rowe, M

- Stewart, Aimee

- Van Aswegen, Heleen

Van Rooijen, Tania
Dr Ina Diener recently represented the SASP at an International Summit on Direct Access and Advance Scope of Physiotherapy in Washington DC. She shares with us what she presented and experienced at the summit.

\section{The First Line Practitioner Status of South African Physiotherapists}

$\mathbf{P}$ hysiotherapists in South Africa were first recognised as First Line Practitioners in 1985. The current regulating body of physiotherapists, the HPCSA, verified the first line practitioner status of physiotherapists in 1997. A position Paper ${ }^{1}$ was tabled in 1998 and revised in 2008: THE FIRST LINE PRACTITIONER STATUS OF SOUTH AFRICAN PHYSIOTHERAPISTS. All physiotherapists registered with the HPCSA are considered first line practitioners, thus working in open and equal partnership with medical and other health care practitioners, in the care of their patients. A first line status practitioner has the autonomy to make an independent diagnosis and treat such a condition, provided it falls within his/her scope of practice. Should the condition fall outside of their scope of practice, a practitioner should refer to an appropriate health care practitioner. It is therefore legally and ethically acceptable for a patient to approach a physiotherapist for treatment without the intervention of another health care practitioner ${ }^{1}$. Such autonomous practice carries a great deal of responsibility. Autonomy is a negotiated, social contract between a profession and policy makers, based on the public trust in a profession to act in the best interests of the society ${ }^{2}$.

Autonomy of action is based on professional standards, as well as advanced knowledge and skill. Professional standards rests on the ethical integrity of the individual, but is also laid down by the profession. The body that protects the public from professional misconduct and malpractice, and controls standards of training/ education for the profession, is the Board for Physiotherapy, Podiatry and Biokinetics of the HPCSA. The professional association (SASP), on the other hand, acts as the authoritative voice in technical matters, reflecting its members' unrivalled expertise ${ }^{1}$. It affords protection for its members, guarding their interests (politically, socially, financially and legally). Secondly, autonomous practice should be based upon a substantial body of advanced theoretical knowledge and skill. There should be a professional and legal obligation to update this knowledge and to keep abreast of new developments, substantiating this knowledge base with evidence from research.

Several studies have demonstrated the ability of physiotherapists to handle direct access $^{3}$. In a study by Jette et al ${ }^{4}$, physiotherapists with an orthopedic specialization, was found to make correct decisions for critical medical and musculoskeletal conditions. Aiken \& $\mathrm{McColl}^{5}$ determined a $90 \%$ diagnostic concordance, $75 \%$ diagnostic accuracy, and $87 \%$ treatment concordance between a physiotherapist and orthopedic surgeon. In a collaborative care context therefore, these studies suggest that appropriately trained physiotherapists have similar diagnostic capabilities to orthopedic surgeons, and they will enhance the conservative treatment options offered to ortho- 
pedic patients. Regardless of where physiotherapists play their primary care roles, there is evidence that direct access and early treatment of musculoskeletal soft tissue injuries by physiotherapists produces favorable outcomes in three ways. The first is therapeutic effectiveness. Here, research shows that primary care physiotherapists are as effective as doctors 6,7 at diagnosing musculoskeletal soft tissue injuries and improving functional outcomes ${ }^{8}$. The second improved outcome, cost effectiveness, is centered on time loss-from-work, since it accounts for up to two-fifths of the cost of managing musculoskeletal injuries ${ }^{9}$. This is a strong financial case for early physiotherapy intervention in soft tissue injuries.

\section{What does this mean for us in South Africa, today?}

1. We need to be part of the main stream health care services by the profession's dedication to public health, with a clear professional identity, and a fidelity to our social contract, which demands that each professional places the wellbeing of society and the patient ahead of the profession and professional.

2. The profession needs to focus on prevention. "There is no guess work when it comes to knowing that our children today as well as their parents are living with one or more significant lifestyle risk factors for various noncommunicable diseases. The good news is that the evidence unequivocally supports the effectiveness and superiority of noninvasive interventions consistent with contemporary physical therapy practice in the promotion of health and wellness, prevention as well as remediation, and life long health and wellbeing"10.

3. The profession needs to ensure adequate training for diagnosis and differentiation. Autonomous practice demands academic programs which prepare newly qualifieds for direct access. Further specialisation in a particular field will advance the primary health care role of the physiotherapist.

\section{References}

SASP, South Africa. 2008. The First Line Practitioner Status of Physiotherapists: Position Paper. Sandstrom RW. 2007. The meanings of autonomy for physical therapy. Phys Ther. 87:98-110.

Daker-White G, Carr AJ, Harvey I, et al. 1999. A randomized controlled trial. Shifting boundaries of doctors and physiotherapists in orthopaedic outpatient departments. J Epidemiol Community Health. 53:643-650

Jette DU, Ardleigh K, Chandler K and McShea L. 2006. Decision-Making Ability of Physical Therapists: Physical Therapy Intervention or Medical Referral. PHYS THER Vol. 86:12

Aiken, AB \& McColl MA. 2008. Diagnostic and treatment concordance between a physiotherapist and an orthopedic surgeon - A pilot study. Journal of Interprofessional Care, 22:3, 253-261

Moore JH, Goss DL, Baxter RE, et al. 2005 Clinical diagnostic accuracy and magnetic resonance imaging of patients referred by physical therapists, orthopaedic surgeons, and non-orthopaedic providers. J Orthop Sports Phys Ther. 35:67-71

Jibuike OO, Paul-Taylor G, Maulvi S et al. 2003. Management of soft tissue injuries in an accident and emergency department: the effect of the introduction of a physiotherapy practitioner. Emerg Med J. 20:37-39

Pinnington MA, Miler J, Stanley I. 2004. An evaluation of prompt access to physiotherapy in the management of low back pain in primary care. Fam Prac. 21:372-380

Mantyselka PT, Kumpusalo EA, Ahonen RS, et al. 2002. Direct and indirect costs of managing patients with musculoskeletal pain-challenge for health care. Eur J Pain. 6:141-148

Dean Elizabeth. 2009. Editorial - Physiotherapy Theory and Practice. Vol. 25:5-6 


\title{
Research \\ Article \\ Reliability of ultrasound imaging for the measurement of abdominal muscle thickness in typically developing children
}

\begin{abstract}
Introduction: Abdominal muscles are key to both posture and gait in both children with typical development (TD) and with disabilities. Ultrasound (US) imaging is a potential non-invasive method for investigating activity in these muscles. This study therefore aimed to determine the intertester and intra-tester reliability of B-mode US for investigating transverse abdominus (TrA), rectus abdominus (RA) and external- (EO) and internal oblique (IO) muscle activity in children with TD. Design: A prospective correlational descriptive study. Participants: Eighty six, 6-13year old children from one private and one public mainstream school. Outcome measures: Two sets of B-mode US images where captured per subject during rest and during head-up, resisted head-up and resisted sling activities. Intra-class Correlation Coefficients (ICC) and standard error of measurement (SEM) were used to analyse the data. Results: Good correlation was found for both test - retest conditions for all four muscles tested during rest: 0.91(TrA); 0.90(IO); 0.91(EO); 0.94(RA) for intra-tester reliability and 0.74(TrA); 0.88(IO); 0.74(EO);0.83(RA) for inter-tester reliability. Repeatability of thickness measures during activity however showed variation in recruitment patterns. A significant correlation was found between age and BMI and resting abdominal muscle thickness $(p<0.001)$. Conclusion: The study supports the reliability of US measurement of resting abdominal muscles and of the $R A$ under active conditions in children aged six to 13. However the stability of measurement of the other muscles under active conditions still needs to be established.
\end{abstract}

KEYWORDS: ULTRASOUND IMA GING, RELIABILITY, ABDOMINAL MUSCLES, CHILDREN. 
